\title{
Reality of having bed nets at home, their status and pattern of using it at night among the population of Lakhantari Village Development Committee of Nepal
}

\author{
Bijay Thapa, ${ }^{1}$ Kapil Kumar Pokharel, ${ }^{2}$ Nitendra Chaurasia, ${ }^{3}$ Alok Acharya, ${ }^{3}$ Rimu Mishra, ${ }^{3}$ Ganesh \\ Sharma $^{4}$ \\ 1Department of Community Health Science, School of Public Health,Lalitpur, Patan, ${ }^{2}$ Department of \\ General Practice and Emergency Medicine, B.P. Koirala Institute of Health Sciences, Dharan, Nepal, \\ ${ }^{3}$ Department of Community Medicine, Nobel Medical College, Biratnagar, Nepal ${ }^{4}$ USAID $\backslash$ CAMRIS \\ International, Baluwatar, Kathmandu, Nepal
}

\section{Correspondence}

Dr. Bijay Thapa

Assistant Professor, Patan

Academy of Health Sciences,

Lalitpur, Patan

Email:

academia4bt@hotmail.com

DOI: http://dx.doi.org/10.3126/ jcmsn.v14i1.18838

Orcid ID: orcid.org/0000-0001 $-5670-2771$

Article received: Dec $31^{\text {st }} 2017$ Article accepted: $\operatorname{Mar} 24^{\text {th }} 2018$

\begin{abstract}
Background \& Objectives: The use of insecticide treated nets has been advocated for the prevention of the vector borne transmitted disease (malaria) by the World Health Organization and UNICEF for more than a decade. In spite of this, there is no significant reduction in the transmission of the disease. Main objectives of study were to find out the real pattern of using it, to find out the physical integrity of the bed nets being used, and to prove the correlation in between the physical integrity of bed nets and the disease outcome. Torn bed nets with holes size more than $1.2 \mathrm{~mm}$ were considered as "holes" in this study. Materials \& Methods: A community based cross- sectional study was carried out in Lakhantari VDC within the duration of two weeks. This VDC has been named recently as Gramthan Gaupalika one of State one. Sample size of 384 was determined by the WHO sample size calculator. Face to face interview technique was used after taking consent from individual. Confidentiality was maintained. It was ethically approved by the IRC (Institutional Review Committee) of Nobel Medical College. Results: A total of 384 household were studied. Total household had bed nets but the physical integrity of bed nets was not intact. Almost $73 \%$ of the bed nets were torn having more than four holes in them. Nearly $94 \%$ of household used bed nets only for three to four days a week. Nearly half of the Malaria was found among $22 \%$ and encephalitis in $17 \%$ of household. Conclusion: Use of bed nets do not prevent and provide guarantee from vector borne disease unless it is properly used. Torn bed nets are of almost no use unless people are using other preventive measures.

Key words: Bed nets; utilization; febrile illness
\end{abstract}

Citation: Thapa B, Pokharel KK, Chaurasia N, Acharya A, Mishra R, Sharma G. Reality of having bed nets at home, their status and pattern of using it at night among the population of Lakhantari Village Development Committee of Nepal. JCMS Nepal. 2018;14(1):39-43.

\section{INTRODUCTION}

There are many mosquitoes borne diseases like Malaria, Dengue and Japanese Encephalitis which still are the main threat despite decades of control efforts made by the government of Nepal. In the past decade, malaria incidence has fallen by at least 50 percent because of government's effort. These gains were because of the active implementation of different vector control program and through a combination of interventions, including timely diagnosis and treatment using reliable tests and antimalarial drugs; indoor spraying with safe insecticides; and the use of LLINS (long lasting insecticide treated nets) to protect people from mosquito bites at night. Easily available treatment for pregnant women and integrated management of vector control method are the main strategies for malaria prevention in Nepal. ITNs (insecticide treated bed nets) distributed free-of-charge has been in existence in households in Nepal. ITNs are always 
being distributed in the country free-of-charge to pregnant women. The use of insecticide treated nets has been advocated for the prevention of the vector borne transmitted disease (malaria) by the World Health Organization and UNICEF for more than a decade. In spite of this, there is no significant reduction in the transmission of the disease. This makes it desirable to obtain answers to some pertinent questions on the transmission of these diseases such as, is the bed nets preventive strategy recommended by the government being used, or is it ineffective. Furthermore, mosquito net ownership in itself is not synonymous with utilization of nets. Proper utilization of net has been not much focused. The present study seeks to determine the presence of bed nets, pattern of using bed nets and the physical integrity of those bed nets.

\section{MATERIALS AND METHODS}

Community based quantitative cross-sectional study was carried out in Lakhantari VDC which has been now changed into Gramthan Gaupalika- one, within one month of duration. Sample size of 384 was determined by the WHO sample size calculator. ${ }^{1}$ The calculation for required sample size was as follows: $\mathrm{p}=0.5$ and hence $\mathrm{q}=1-0.5=0.5$; e $=0.05 ; \mathrm{z}=1.96$. Where, $\mathrm{p}=$ prevalence, $\mathrm{q}=1-\mathrm{p}, \mathrm{e}=$ margin of error, $\mathrm{z}=$ sample power, and level of $\alpha=z$. Main objectives of study were to find out the real pattern of using it, to find out the physical integrity of the bed nets being used, and to prove the correlation in between the physical integrity of bed nets and the disease outcome. Pretested questionnaires were administered to head of household $(\mathrm{HOH})$ which consisted of demographic information, availability of bed nets, and pattern of their effective use. Torn bed nets with holes size more than $1.2 \mathrm{~mm}$ or 25 holes $/ \mathrm{cm}^{2}$ were considered as "holes" in this study. All data collected were entered into SPSS (Statistical Package for the Social Sciences) version 16 for analyses. Associations between the use and condition of LLINs, numbers of holes, age, how often the nets were changed and newly bought, pattern of using LLINs, level of education, and malaria or other disease along with the febrile illness symptom's prevalence were evaluated using Pearson Chi Square $\left(\chi^{2}\right)$ test. It was ethically approved by the IRC of Nobel Medical College.

\section{RESULTS}

A total of 384 household were studied. There were
54 Females as a head of household comprising only $14 \%$. The ages of these $\mathrm{HOH}$ ranged between 21 years and 77 years and the mean age was 47.52. More than half of household were of extended type having third generation family members which was more than $54 \%$. One fourth of the household were nuclear type. The family members in the family ranged from 2 to 9. More than one third of the $\mathrm{HOH}$ were factory worker. Half of the $\mathrm{HOH}$ were illiterate comprising $49.5 \%$. But one third of the $\mathrm{HOH}$ were educated up to primary level. The demography profile of household and head of household studied is shown in Table 1.

Table no. 2 is showing the relationship in between the number of holes found in bed nets, frequency of using bed nets and the present of febrile illness amongst the household members. Febrile symptoms were mainly found among those household who had more than four holes in their bed nets comprising of sixty percent. Febrile illness was mostly found among $36.2 \%$ household with usage of bed nets less than three days a week.

Results not shown in article are related to the number of pregnant women, color of the bed nets, frequency of number of holes in the bed nets and the diagnosis of the disease with febrile illness. Only 4 household had pregnant women comprising of single in each household. The color of the bed nets used by the households. Most of the household had light blue colored bed nets which comprised $39 \%$ followed by white, purple and brown having $25 \%, 20 \%$ and $16 \%$ accordingly.

Total households were having bed nets. Nearly $9 \%$ households had intact bed nets with no holes found. At least one hole was found among $4.4 \%$ of households. Twenty five percent of household had minimum of three holes in their bed nets. One percent of household had minimum nine holes or torn at nine places in their bed nets. Among 17.2\% household four and five holes were found. Mean holes number found was 3.5 among household's bed nets.

Typhoid was the most diagnosed disease comprising of $61 \%$ followed by malaria among $22 \%$ and encephalitis in $17 \%$ of household among total of 36 households.

Figure 1 is a summary of duration of using the same bed nets by the members of household. Nearly $41 \%$ bed nets were used for 3 to 4 years followed by $29.4 \%$ and $19.2 \%$ for 2 to 3 and 1 to 2 years. Almost 9\% of household were using bed nets for 


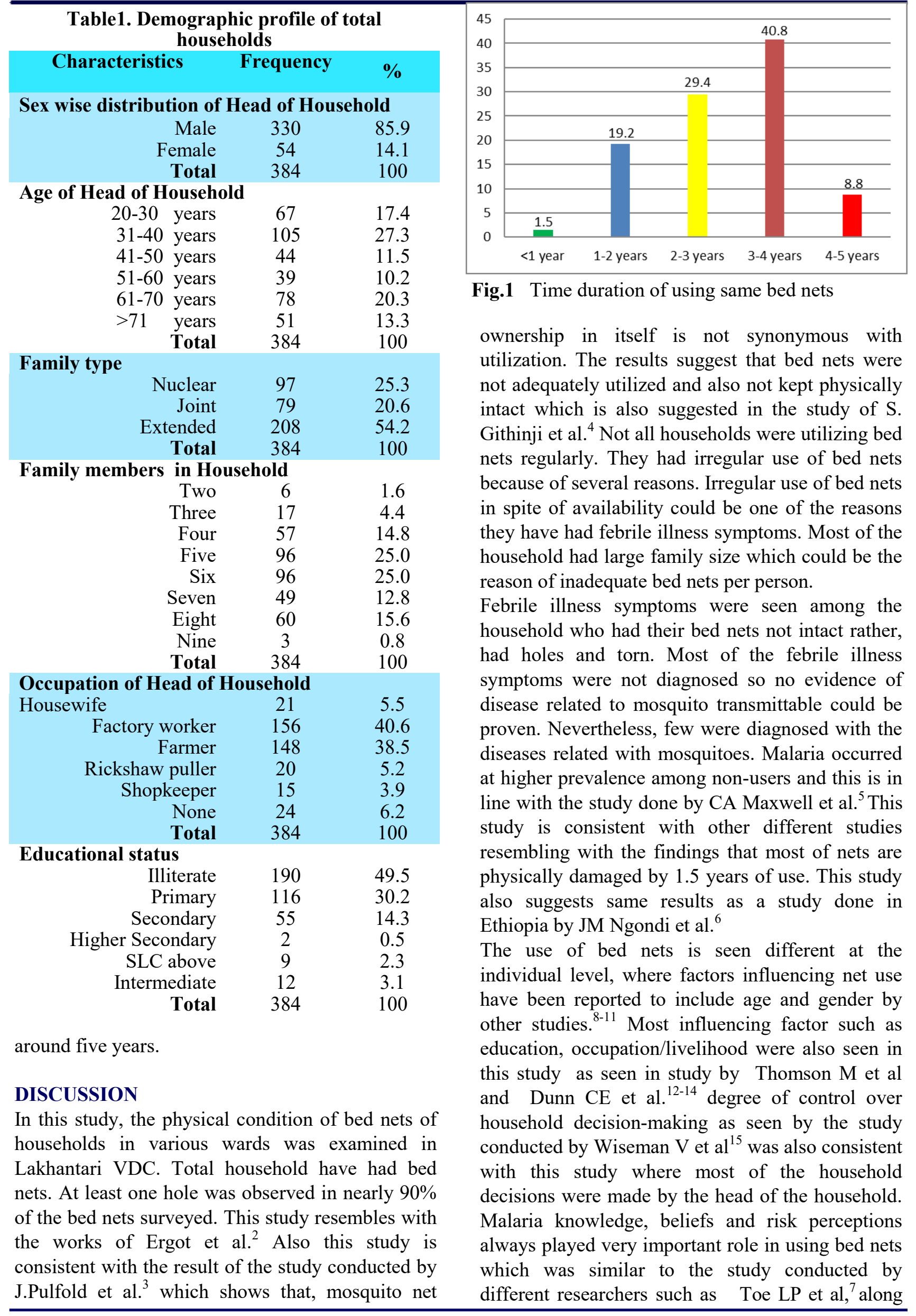


Table no. 2 Relation between Febrile symptoms at household and holes in bed nets

\begin{tabular}{|c|c|c|c|c|c|c|c|}
\hline \multirow[b]{2}{*}{ Number of holes } & \multicolumn{4}{|c|}{ Febrile symptoms } & \multirow{2}{*}{\multicolumn{2}{|c|}{ Total }} & \multirow{2}{*}{$P$ value } \\
\hline & No & $\%$ & Yes & $\%$ & & & \\
\hline$\leq 3$ holes & 90 & $23.4 \%$ & 14 & $3.6 \%$ & 104 & $27.1 \%$ & \multirow{3}{*}{$<0.001 *$} \\
\hline \multirow[t]{2}{*}{$\geq 4$ holes } & 51 & $13.3 \%$ & 229 & $59.6 \%$ & 280 & $72.9 \%$ & \\
\hline & 141 & $36.7 \%$ & 243 & $63.3 \%$ & 384 & $100.0 \%$ & \\
\hline \multicolumn{8}{|l|}{ Frequency of using bed nets } \\
\hline 0-3 days/week & 51 & $13.3 \%$ & 139 & $36.2 \%$ & 190 & $49.5 \%$ & \multirow{3}{*}{$<0.001$ * } \\
\hline 4-7days/week & 90 & $23.4 \%$ & 104 & $27.1 \%$ & 194 & $50.5 \%$ & \\
\hline Total & 141 & $36.7 \%$ & 243 & $63.3 \%$ & 384 & $100.0 \%$ & \\
\hline
\end{tabular}

$* P$ value $\leq 0.05$ is significant

with Hwang $\mathrm{J}$ et al. ${ }^{16}$ In this study people used bed nets according to the knowledge on perceived benefits and disadvantages of nets also consisted with the study of Adongo P et al, Ng'ang'a PN et al and Widmar $\mathrm{M}$ et al. ${ }^{7,17-19}$

\section{CONCLUSION}

Use of bed nets do not prevent and provide guarantee from vector borne disease unless it is properly used. Torn bed nets are of almost no use unless people are using other preventive measures. People may use bed nets for the sake of using it in spite of being aware of the physical integrity of it. That may be because people cannot afford to change the bed nets as per need. Further step proposing a more systematic evaluation of the incidence of disease and the physical integrity and the pattern of the bed nets used by the community people is needed. This knowledge from this study shows that people are needed to be made aware about the proper way of using and replacing older bed nets per need.

Acknowledgements: We are grateful to all the pregnant women and the households who gave their consent to participate in the study. We also acknowledge Nobel Medical College for financial and technical support and Lakhantari VDC office and DPHO Biratnagar for permitting conducting the research. Students of Nobel Medical College are highly acknowledged for their support.

\section{Funding}

None

Conflict of Interest Statement:

None Declared

\section{REFERENCES}

1. Lwanga SK. Sample size determination in health studies: a practical manual, WHO,1991.
2. Egrot $\mathrm{M}$, Houngnihin $\mathrm{R}$, Baxerres $\mathrm{C}$, Damien $\mathrm{G}$, Djènontin $\mathrm{A}$, Chandre $\mathrm{F}$, et al. Reports of long-lasting insecticidal bed nets catching on fire: a threat to bed net users and to successful malaria control? Malar J. 2014;13:247. https://doi.org/10.1186/1475-2875-13247. PMID: 24972637.

3. Pulford J, Hetzel MW, Bryant M, Siba PM, Mueller I. Reported reasons for not using a mosquito net when one is available: a review of the published literature. Malar J. 2011;10:83. https:// doi.org/10.1186/1475-2875-10-83. PMID: 21477376.

4. Graves PM, Ngondi JM, Hwang J, Getachew A, Gebre T, Mosher AW, et al. Factors associated with mosquito net use by individuals in households owning nets in Ethiopia. Malar J. 2011;10:354 https://doi.org/10.1186/1475-2875-10-354. PMID: 22165821.

5. Maxwell CA, Rwegoshora RT, Magesa SM, Curtis $\mathrm{CF}$ : Comparison of coverage with insecticide-treated nets in a Tanzanian town and villages where nets and insecticide are either marketed or provided free of charge. Malar J. 2006;5:44.https:// doi.org/10.1186/1475-2875-5-44. PMID: 16712738 .

6. Ngondi JM, Graves PM, Gebre T, Mosher AW, Shargie EB, Emerson PM, et al. Which nets are being used: factors associated with mosquito net use in Amhara, Oromia and Southern Nations, Nationalities and Peoples' Regions of Ethiopia. Malar J. 2011;10:92. https://doi.org/10.1186/1475-2875-1092. PMID: 21496331

7. Toé LP, Skovmand O, Dabire KR, Diabate A, Diallo Y, Guiguemde TR, et al. Decreased motivation in the use of insecticide-treated nets in a malaria endemic area in Burkina Faso. Malar J. 2009;8:175. https:// doi.org/10.1186/1475-2875-8-175. PMID: 19640290.

8. Alaii JA, Hawley WA, Kolczak MS, ter Kuile FO, Gimnig JE, Vulule JM, et al. Factors affecting use of permethrin-treated bed nets during a randomized controlled trial in western Kenya. Am J Trop Med Hyg. 2003;68:137-41. PMID: 12749497.

9. Eisele TP, Keating J, Littrell M, Larsen D, Macintyre $\mathrm{K}$. Assessment of insecticide-treated bednet use among children and pregnant women across 15 countries using standardized national surveys. Am J Trop Med Hyg. 2009;80:209-14. PMID: 19190215.

10. Baume CA, Marin MC. Intra-household mosquito net use in Ethiopia, Ghana, Mali, Nigeria, Senegal, and Zambia: are nets being used? Who in the household uses them? Am J Trop Med Hyg. 2007;77:963-71. 
PMID: 17984361.

11. Rashed S, Johnson H, Dongier P, Moreau R, Lee C, Crepeau R. Determinants of the Permethrin Impregnated Bednets (PIB) in the Republic of Benin: the role of women in the acquisition and utilization of PIBs. Soc Sci Med. 1999;49:993-1005. https:// doi.org/10.1016/S0277-9536(99)00152-5.

12. Thomson M, Connor S, Bennett S, D'Alessandro U, Milligan P, Aikins $M$, et al. Geographical perspectives on bednet use and malaria transmission in The Gambia, West Africa. Soc Sci Med. 1996; 43:101-112. https://doi.org/10.1016/0277-9536(95) 00346-0.

13. MacCormack CP, Snow RW. Gambian cultural preferences in the use of insecticide-impregnated bed nets. J Trop Med Hyg. 1986;89:295-302. PMID: 3806747.

14. Dunn CE, Le Mare A, Makungu C. Malaria risk behaviours, socio-cultural practices and rural livelihoods in southern Tanzania: implications for bednet usage. Soc Sci Med. 2011;72:408-17. https://doi.org/10.1016/j.socscimed.2010.11.009. PMID: 21211875.

15. Wiseman V, Scott A, McElroy B, Conteh L, Stevens W. Determinants of bed net use in The Gambia: Implications for malaria control. Am J Trop Med Hyg. 2007;76:830-6. PMID: 17488900.

16. Hwang J, Graves PM, Jima D, Reithinger R, Kachur SP: Knowledge of malaria and its association with malaria-related behaviors-results from the Malaria Indicator Survey, Ethiopia, 2007. PLoS One. 2010, 5:e11692. https://doi.org/10.1371/ journal.pone.0011692. PMID: 20657782.

17. Adongo P, Kirkwood B, Kendall C. How local community knowledge about malaria affects insecticide treated net use in northern Ghana MIMPA-238950. Acta Trop. 2005, 95:S49-S50.

18. Ng'ang'a PN, Jayasinghe G, Kimani V, Shililu J, Kabutha C, Kabuage L, et al. Bed net use and associated factors in a rice farming community in Central Kenya. Malar J. 2009;8. https:// doi.org/10.1186/1475-2875-8-64.

19. Widmar M, Nagel CJ, Ho DY, Benziger PW, Hennig $\mathrm{N}$. Determining and addressing obstacles to the effective use of long-lasting insecticide impregnated nets in rural Tanzania. Malar J. 2009;8. https://doi.org/10.1186/1475-2875-8-315. 